\title{
POLYHYDROXYALKANOATES/ ALFA FIBERS BIO-COMPOSITES: ELABORATION AND MECHANICAL TESTING
}

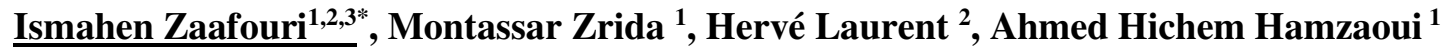 \\ ${ }^{1}$ Centre National de Recherches en Sciences des Matériaux, Laboratoire de Valorisation des Matériaux \\ Utiles, B.P. 73, 8027 Soliman, Tunisie \\ ${ }^{2}$ Univ. Bretagne Sud, UMR CNRS 6027, IRDL, F-56100 Lorient, France \\ ${ }^{3}$ Université de Monastir, Ecole Nationale d’Ingénieurs de Monastir, Rue Ibn El Jazzar - Monastir - \\ 5000 Rue Ibn Jazzar, Monastir 5035, Tunisie \\ * ismahen.zaafouri@univ-ubs.fr
}

Polymers synthesized from natural resources have attracted considerable interest in the recent years. The aim of the present study is to develop and characterize new bio-composites based on PolyHydroxyAlkanoates (PHA) polymer and different percentage of cellulose fibers (from 0\% to $30 \%$ ) extracted from the Alfa plant (see figure 1). PHAs are fully biodegradable and biocompatible since they are produced entirely from renewable carbon sources [1,2]. However, although having promising properties, PHAs are unstable during processing at elevated temperatures causing thermal degradation which reduces their mechanical performance. By introducing cellulose from Alfa fibers, the goal is to improve the mechanical behaviour of these new composites. To increase the amount of cellulose, fibers were first extracted from Alfa stems using Alkaline methods and then modified through bleaching treatment using Sodium Hypochlorite $\mathrm{NaClO}_{2}$. These fibers were finally mixed with the PHA polymer during the injection of the tensile specimens. The influence on the mechanical behavior of the fiber content was studied by performing tensile tests under different loading conditions (monotonic, cyclic and interrupted by relaxation steps). The final aim is to find the material parameters of a constitutive model named HVH able to describe the Hyper-Visco-Hysteresis behaviour of polymers [3].

a)

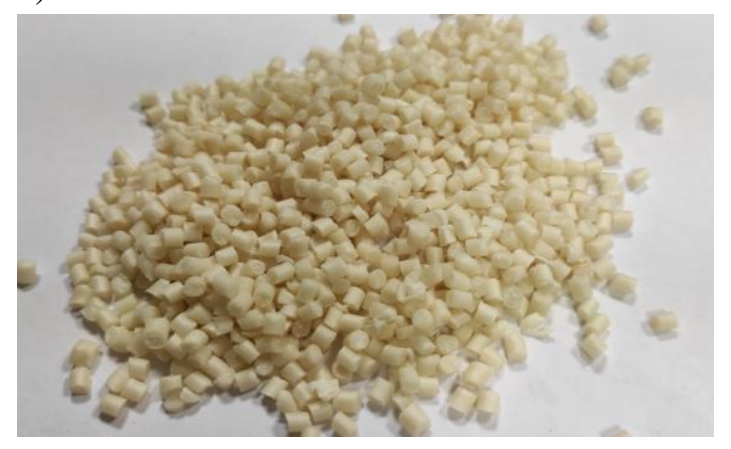

b)

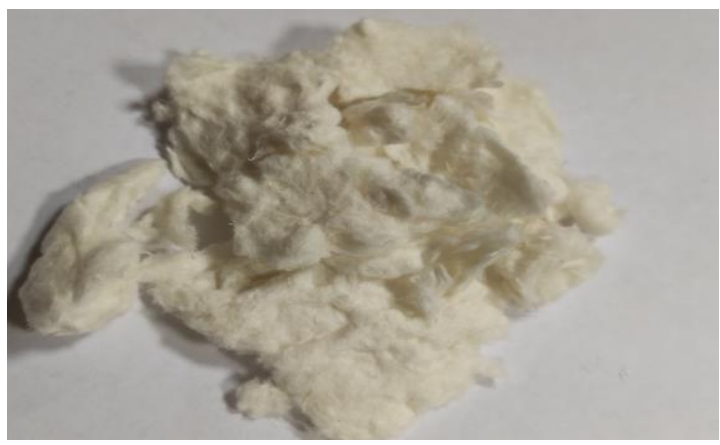

Figure 1. a) PHA polymer, b) Cellulose fibers

\section{References}

[1] R. Sindhu, N. Silviya, P. Binod and A. Pandey (2013) Pentose-rich hydrolysate from acid pretreated rice straw as a carbon source for the production of poly-3-hydroxybutyrate. Biochemical Engineering Journal, 78, 67-72.

[2] R.M.R. Wellen, M.S. Rabello, G.J.M. Fechine and E.L. Canedo (2013) The melting behaviour of poly(3-hydroxybutyrate) by DSC. Reproducibility study Polymer Testing, 32, 215-220.

[3] M. Zrida, H. Laurent and G. Rio. (2016) Numerical Study of Mechanical Behaviour of a Polypropylene Reinforced with Alfa Fibres. Journal of Composite Materials, 50, 2883-93. 